\title{
Coefficient of thermal expansion and elastic modulus of thin films
}

\author{
M. M. de Lima, Jr., ${ }^{\text {a) }}$ R. G. Lacerda, J. Vilcarromero, and F. C. Marques \\ Universidade Estadual de Campinas, Unicamp, Instituto de Física “Gleb Wataghin,", \\ 13083-970 Campinas SP, Brazil
}

(Received 2 June 1998; accepted for publication 19 July 1999)

\begin{abstract}
The coefficient of thermal expansion (CTE), biaxial modulus, and stress of some amorphous semiconductors $\left(a-\mathrm{Si}: \mathrm{H}, a-\mathrm{C}: \mathrm{H}, a-\mathrm{Ge}: \mathrm{H}\right.$, and $\left.a-\mathrm{GeC}_{x}: \mathrm{H}\right)$ and metallic (Ag and $\left.\mathrm{Al}\right)$ thin films were studied. The thermal expansion and the biaxial modulus were measured by the thermally induced bending technique. The stress of the metallic films, deposited by thermal evaporation ( $\mathrm{Ag}$ and $\mathrm{Al}$ ), is tensile, while that of the amorphous films deposited by sputtering $(a-\mathrm{Si}: \mathrm{H}, a-\mathrm{Ge}: \mathrm{H}$, and $\left.a-\mathrm{GeC}_{x}: \mathrm{H}\right)$ and by glow discharge $(a-\mathrm{C}: \mathrm{H})$ is compressive. We observed that the coefficient of thermal expansion of the tetrahedral amorphous thin films prepared in this work, as well as that of the films reported in literature, depend on the network strain. The CTE of tensile films is smaller than that of their corresponding crystalline semiconductors, but it is higher for compressive films. On the other hand, we found out that the elastic biaxial modulus of the amorphous and metallic films is systematically smaller than that of their crystalline counterparts. This behavior stands for other films reported in the literature that were prepared by different techniques and deposition conditions. These differences were attributed to the reduction of the coordination number and to the presence of defects, such as voids and dangling bonds, in amorphous films. On the other hand, columnar structure and microcrystallinity account for the reduced elasticity of the metallic films. (C) 1999 American Institute of Physics. [S0021-8979(99)01021-X]
\end{abstract}

\section{INTRODUCTION}

Thin films have been used in a large variety of technological applications such as solar cells, antireflective coatings, field effect transistors, position sensors, optical waveguides, optical memories, strain gauges, photolitographic masks, protective coatings, and electric contacts. The knowledge about the mechanical properties of these materials, such as the stress, the elastic modulus, and the coefficient of thermal expansion (CTE), is of great interest since these parameters are important to determine the stability and reliability of the devices manufactured.

The stress developed in amorphous materials creates defects such as pinholes and cracks, which hinders its use in technological applications. For instance, diamond-like carbon films with thickness higher than few tenths of microns peel off the substrate with time due to their high stress. ${ }^{1}$ There are different sources of stress: (1) in amorphous films prepared at high temperature, thermal stress is generated due to the difference in the CTE of the film and substrate. ${ }^{2}$ In order to reduce the thermal stress a good match between the expansion coefficient of the film and substrate is required. The intensity of the thermal stress also depends on the elastic modulus; (2) the film + substrate interface is also a source of stress, known as interfacial stress, which appears due to differences between structural properties of the film and substrate; and (3) the growth mechanism generates stress in the bulk of the films, the intrinsic stress, which depends on the technique used and on the preparation conditions. ${ }^{3,4}$ It is well

\footnotetext{
a) Author to whom correspondence should be addressed; electronic mail: mmlimajr@ifi.unicamp.br
}

accepted that the intrinsic tensile stress is due to some sort of defect, especially voids and columnar structures. The origin of the compressive stress, on the other hand, is not clear yet, but it is apparently associated with the presence of contaminants, such as argon, oxygen, and hydrogen. ${ }^{5}$

The stress of amorphous thin films has been measured by a number of techniques such as x-ray diffraction, ${ }^{4,6} \mathrm{Ra}$ man spectroscopy, ${ }^{7}$ mechanical profilometry, ${ }^{5,8-10}$ and the bending beam method. ${ }^{4}$ The elastic constants have been determined by nanoindentation, ${ }^{11,12}$ Brillouin scattering, ${ }^{13}$ and acoustic microscopy. ${ }^{14}$ Since the Young's modulus and the Poisson ratio always appear combined, they cannot be obtained using just one of the above mentioned techniques. In order to obtain these parameters one needs to use at least two different techniques. For example, using nanoindentation and Brillouin scattering, Jiang et al. determined $E$ and $\nu$ separately for $a-\mathrm{C}: \mathrm{H}$ (Ref. 8) and $a-\mathrm{Si}: \mathrm{H}^{9}$ The CTEs of $a$-Si:H, ${ }^{15-17} a-\mathrm{Ge}: \mathrm{H}^{5,15} a-\mathrm{C}: \mathrm{H}^{18}{ }^{18} a-\mathrm{Ge}_{1-x} \mathrm{~N}_{x}: \mathrm{H},{ }^{19,20}$ $a-\mathrm{Si}_{1-x} \mathrm{O}_{x}: \mathrm{H},{ }^{16} \mathrm{Al},{ }^{21}$ and $\mathrm{Cr},{ }^{22}$ have been obtained using a technique, thermally induced bending (TIB), based on the determination of the curvature of the film + substrate composite as a function of temperature. Recently, x-ray diffraction $^{23}$ and dilatometry ${ }^{24}$ have also been used to determine the thermal expansion coefficients of some metallic films.

However, very little is known about the CTE of thin films, for both amorphous and polycrystalline. In addition, there are no theoretical or experimental systematic studies to explain the CTE of thin films. The reason is probably due to the lack of experimental data. For instance, there is only a couple of data reported for $a-\mathrm{Si}: \mathrm{H}$ and $a-\mathrm{Ge}: \mathrm{H}$ which are two of the most studied amorphous semiconductors. ${ }^{5,15-17}$ 
TABLE I. Thickness, biaxial modulus, and coefficient of thermal expansion of the substrates used to determine the biaxial modulus and coefficient of thermal expansion of the thin films mentioned in Sec. II A.

\begin{tabular}{cccc}
\hline \hline & $\begin{array}{c}\text { Biaxial } \\
\text { modulus } \\
(\mathrm{GPa})\end{array}$ & $\begin{array}{c}\mathrm{CTE} \\
\left(10^{-6}{ }^{\circ} \mathrm{C}^{-1}\right)\end{array}$ & $\begin{array}{c}\text { Thickness } \\
(\mathrm{mm})\end{array}$ \\
\hline $\begin{array}{c}\text { Substrate } \\
\langle 111\rangle \\
\text { Germanium } \\
\langle 111\rangle\end{array}$ & $229^{\mathrm{a}}$ & $2.6^{\mathrm{d}}$ & 0.38 \\
$\begin{array}{c}7059 \\
\text { Corning Glass } \\
211\end{array}$ & $184^{\mathrm{a}}$ & $6.0^{\mathrm{e}}$ & 0.37 \\
Precision Glass & $95.7^{\mathrm{b}}$ & $4.6^{\mathrm{b}}$ & 0.41 \\
\hline \hline
\end{tabular}

${ }^{\mathrm{a}}$ See Ref. 34.

${ }^{\mathrm{b}}$ See Ref. 37.

${ }^{\mathrm{c}} \mathrm{See}$ Ref. 38.

${ }^{\mathrm{d}}$ See Ref. 35

${ }^{\mathrm{e} S e e}$ Ref. 36.

Although it is well known that the thermomechanical properties of thin films are strongly related to the film structure such as defects, voids, network strain, and the mean coordination number, a complete study relating these properties has not yet been reported. Therefore, it is of fundamental importance to determine the dependence of the biaxial modulus and CTE of amorphous semiconductors and metallic films on the film structure. The main purpose of this article is to provide an analysis of the biaxial modulus and the coefficient of thermal expansion of several amorphous semiconductors and metallic thin films.

\section{EXPERIMENT}

\section{A. Sample preparation}

The $a-\mathrm{C}: \mathrm{H}$ films were deposited by methane plasma decomposition. $^{25}$ All the other amorphous semiconductors were deposited in a Leybold-Heraeus Z-400 rf sputtering system. Argon plus hydrogen atmospheres were used for the deposition of the $a-\mathrm{Ge}: \mathrm{H},{ }^{26} a-\mathrm{Si}: \mathrm{H},{ }^{27}$ and $a-\mathrm{Ge}_{0.73} \mathrm{C}_{0.27}: \mathrm{H}$ (Ref. 28) films by sputtering $\mathrm{Ge}, \mathrm{Si}$, and composed $\mathrm{Ge} / \mathrm{C}$ targets, respectively. The $\mathrm{Ag}$ and $\mathrm{Al}$ films were deposited at $5 \times 10^{-6}$ mbar pressure, at room temperature, by conventional thermal evaporation. For a more detailed description concerning the preparation conditions of the above mentioned amorphous semiconductors the readers are referred to the references cited. The structure of the Ag and Al films has not been checked. However, detailed descriptions of the structure of metallic films, including samples prepared under similar conditions, are found in Refs. 29-33. The film thickness, measured by an Alfa Step profilometer, is in the 0.4$4.8 \mu \mathrm{m}$ range. The typical deposition rates were from 0.5 to $2.0 \AA / \mathrm{s}$, except for the silver and aluminum films, which were deposited at approximately $20 \AA / \mathrm{s}$. The films were deposited on different substrate strips $\left(25 \times 4 \mathrm{~mm}^{2}\right)$, at the same run. Table I shows the elastic properties, CTE, and thickness of the substrates adopted. ${ }^{34-38}$

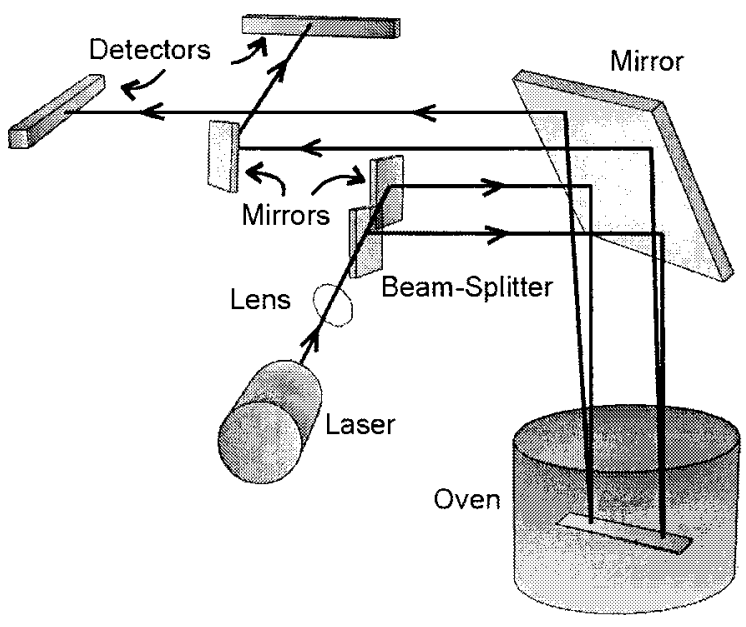

FIG. 1. Schematic diagram of the apparatus used to determine the curvature as a function of temperature.

\section{B. Coefficient of thermal expansion and biaxial modulus measurements}

In this work, several films have been prepared and measured by the TIB technique. Using only this technique, one can determine simultaneously the stress, the biaxial modulus $E /(1-\nu)$, and the coefficient of thermal expansion of thin films.

The curvatures of the film + substrate structures were determined by the bending beam method using the system sketched in Fig. 1. ${ }^{39}$ The use of two laser beams allows static measurements, i.e., without any mechanical movement, which is not possible using a single laser beam. This is a great advantage over other reported apparatus in which the curvature is obtained by either scanning a laser beam over a fixed sample or moving the sample while it is being scanned by a stationary laser beam. ${ }^{40-42}$ In these kinds of systems, the measurement of the curvature can be largely influenced by small deviations of either the laser beam or the sample position. The use of two laser beams, as in Fig. 1, avoids this problem. In addition, it substantially reduces the time spent in each measurement, making it possible to continuously acquire data as a function of temperature.

The stress of a thin film, deposited on a substrate, which has a length that is much greater than its width and thickness, is given by the modified Stoney equation: ${ }^{43,44}$

$$
\sigma=\left[E_{s} /\left(1-\nu_{s}\right)\right] t_{s}^{2} / 6 t_{f}\left(1 / R-1 / R_{0}\right),
$$

where $E, \mathrm{v}$, and $t$ are the Young's modulus, Poisson's ratio, and thickness, respectively. The subscripts $s$ and $f$ refer to substrate and film, respectively. $1 / R_{0}$ is the curvature before the film deposition and $1 / R$ is the curvature after the deposition.

Before the curvature measurements a 2-h anneal at $140{ }^{\circ} \mathrm{C}$ was performed under vacuum to obtain a structural relaxation of the samples. This is mainly important for metallic films in order to avoid problems related to yield and flow plasticity. The data were taken during the cooling process (from $140{ }^{\circ} \mathrm{C}$ to room temperature) at a rate of about $1{ }^{\circ} \mathrm{C} / \mathrm{min}$. Figure 2 displays the results obtained for aluminum and silver films deposited on a 7059 Corning Glass 


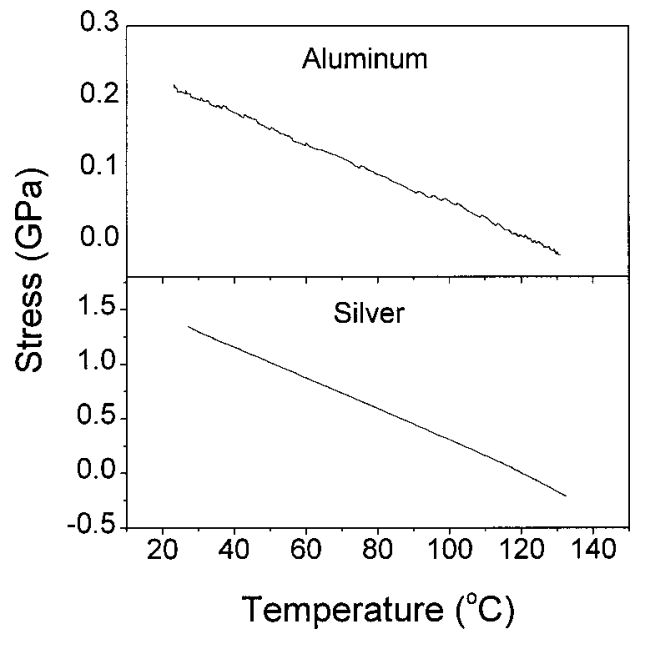

FIG. 2. Temperature dependence of the stress of silver and aluminum films deposited onto 7059 Corning Glass.

substrate. "Continuous" curves could be obtained due to the use of two laser beams adopted in our apparatus setup. Both curves are reasonably linear from room temperature to $100{ }^{\circ} \mathrm{C}$ (a similar behavior was also obtained for the other substrates).

The stress versus temperature dependence is given by the relation ${ }^{2}$

$$
d \sigma / d T=\left[E_{f} /\left(1-\nu_{f}\right)\right]\left(\alpha_{s}-\alpha_{f}\right) .
$$

This equation involves three unknown parameters; $E_{f}, \nu_{f}$, and $\alpha_{f}$. The coefficient of thermal expansion $\alpha_{f}$ and the biaxial modulus $E_{f} /\left(1-\nu_{f}\right)$ can be determined simultaneously, since the temperature dependence on the stress, for the same film deposited on two different substrates is known. They can be readily obtained by solving two equations ${ }^{5,15,16,19,20}$ of the form given in Eq. (2), or by plotting two $E_{f} /\left(1-\nu_{f}\right)$ vs $\alpha_{f}$ curves to find their intersection. ${ }^{45,46}$ In this work, we used more than two substrates to improve the results. ${ }^{18,47,48}$

\section{RESULTS}

Figure 3 shows the stress as a function of temperature of an $a$-Si:H film deposited on different substrates. The negative sign means that the stress is compressive. It can be noticed that the slope of the $\sigma$ vs $T$ curve changes from negative to positive, depending on the CTE of the substrate, according to relation (2). A negative slope means that the thermal expansion of the film is higher than that of the substrate. For instance, Fig. 3 shows that the thermal expansion of $a-\mathrm{Si}: \mathrm{H}$ is higher than that of $c-\mathrm{Si}$. The slopes $d \sigma / d T$ of these curves were plotted against $\alpha_{s}$ (Fig. 4) in order to evidence the linear regression used to obtain the best solution for the set of four equations of the form given in Eq. (2). The slope of the solid curve is the biaxial modulus and the intersection between the solid curve and the $\alpha_{s}$ axis is the CTE of the film.

Adopting this procedure, we determined the above parameters for several semiconductors and metallic thin films (Table II). The stress at room temperature and the film thick-

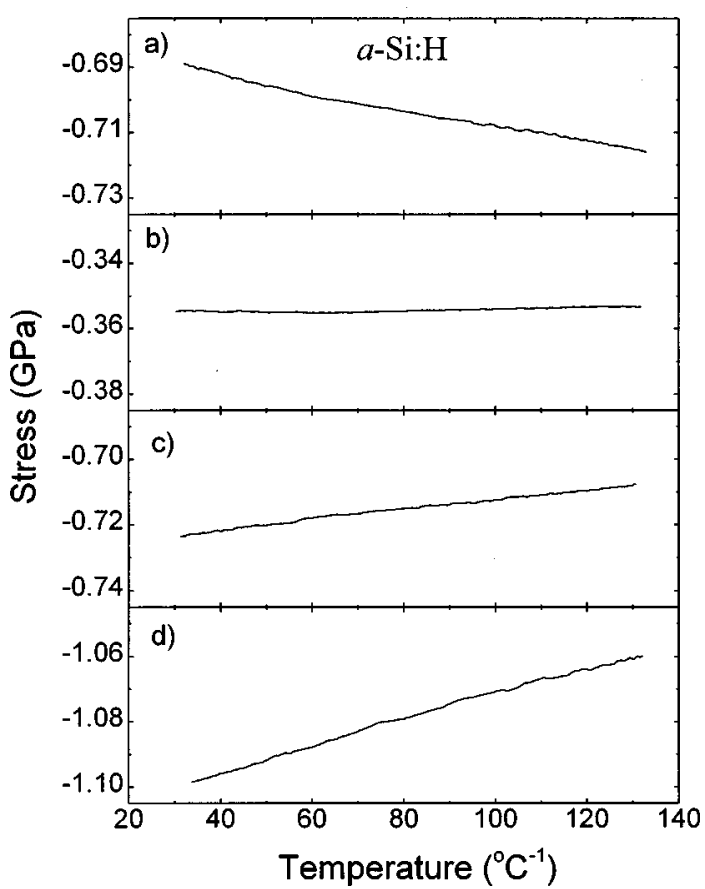

FIG. 3. Temperature dependence of the stress of an $a$-Si:H sample deposited at different substrates: (a) $\langle 111\rangle$ silicon; (b) 7059 corning glass; (c) $\langle 111\rangle$ germanium; and (d) 211 precision glass.

ness are also quoted in Table II. It also includes several data, reported by other laboratories, of thin films prepared and measured by different methods. The works that used techniques such as $\mathrm{x}$-ray diffraction or dilatometry determined only the CTE, since these techniques do not allow obtaining the biaxial modulus. The opposite occurs for nanoindentation and Brillouin scattering measurements, which give only the elastic constants.

The biaxial modulus and the coefficient of thermal expansion are expected to depend on the hydrogen concentration of the hydrogenated amorphous films. In the case of $a-\mathrm{Ge}_{1-x} \mathrm{C}_{x}: \mathrm{H}$ alloys that were prepared in this work, and of other alloys reported in literature, both the biaxial modulus and thermal expansion might also depend on the film composition.

A comparison between the CTE and the biaxial modulus of amorphous and crystalline materials is shown in Figs. 5

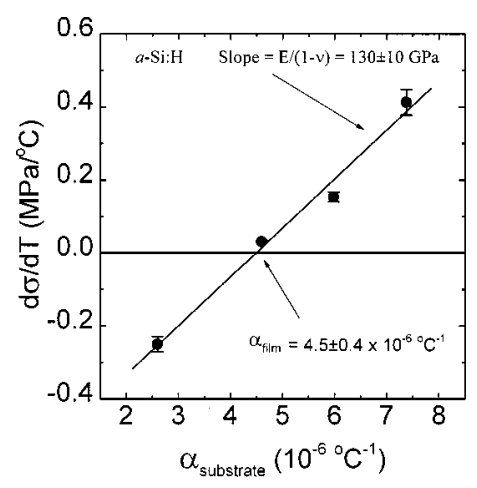

FIG. 4. $d \sigma / d T$ of an $a-\mathrm{Si}: \mathrm{H}$ thin film as a function of the thermal expansion coefficient of the substrates. The straight line is a linear fitting from which the biaxial modulus and thermal expansion coefficient are obtained. 
TABLE II. Biaxial modulus, coefficient of thermal expansion, and stress at room temperature of amorphous semiconductors and metallic thin films studied in this work. The film thickness and the deposition technique are also included.

\begin{tabular}{|c|c|c|c|c|c|c|}
\hline Material & $\begin{array}{l}\text { Stress } \\
(\mathrm{GPa})\end{array}$ & $\begin{array}{l}\text { Biaxial modulus } \\
(\mathrm{GPa})\end{array}$ & $\begin{array}{c}\text { CTE } \\
\left(10^{-6}{ }^{\circ} \mathrm{C}^{-1}\right)\end{array}$ & $\begin{array}{c}\text { Film thickness } \\
(\mu \mathrm{m})\end{array}$ & $\begin{array}{c}\text { Preparation } \\
\text { technique }\end{array}$ & Reference \\
\hline$a-\mathrm{Si}: \mathrm{H}$ & -0.69 & $130 \pm 10$ & $4.5 \pm 0.4$ & 3.6 & rf sputtering & This work \\
\hline$a-\mathrm{Si}: \mathrm{H}$ & -0.3 & $140 \pm 10$ & $3.0 \pm 0.3$ & $\sim 1$ & rf sputtering & 15 \\
\hline$a-\mathrm{Si}: \mathrm{H}$ & - & 150 & 4.4 & $1-10$ & PECVD & 16 \\
\hline$a-\mathrm{Si}: \mathrm{H}$ & -0.14 & 150 & - & 0.5 & rf sputtering & 8 \\
\hline$a-\mathrm{Si}$ & - & 130 & - & 0.27 & ion implanted & 14 \\
\hline$a-\mathrm{Si}$ & +0.15 & 135 & $\sim 2.4$ & 2.1 & ion implanted & 17 \\
\hline$a-\mathrm{Ge}: \mathrm{H}$ & -0.45 & $83 \pm 7$ & $8.0 \pm 0.7$ & 3.0 & rf sputtering & This work \\
\hline$a-\mathrm{Ge}: \mathrm{H}$ & -0.36 & $120 \pm 10$ & $7.9 \pm 0.7$ & $\sim 1$ & rf sputtering & 15 \\
\hline$a-\mathrm{Ge}: \mathrm{H}$ & $\sim-0.3$ & 110 & 7 & $\sim 2$ & PECVD & 5 \\
\hline$a-\mathrm{C}: \mathrm{H}$ & -2.00 & $130 \pm 10$ & $3.0 \pm 0.2$ & 0.84 & PECVD & This work \\
\hline$a-\mathrm{C}: \mathrm{H}$ & -3 & 170 & 2.3 & $0.06-0.08$ & ion-assisted CVD & 18 \\
\hline$a-\mathrm{C}: \mathrm{H}$ & -4 & 180 & - & $>0.5$ & PECVD & 8 \\
\hline$a-\mathrm{C}\left(\sim 16 \% s p^{3} \mathrm{C}-\mathrm{C}\right)$ & - & $250^{\mathrm{a}}$ & - & $0.2-0.5$ & $\begin{array}{l}\text { ion-beam-assisted } \\
\text { magnetron }\end{array}$ & 11 \\
\hline ta- $\mathrm{C}\left(\sim 75 \% s p^{3} \mathrm{C}-\mathrm{C}\right)$ & - & $550^{\mathrm{a}}$ & - & 0.11 & pulsed laser & 12 \\
\hline$a-\mathrm{Ge}_{0.73} \mathrm{C}_{0.27} \mathrm{H}$ & -0.06 & $200 \pm 20$ & $5.5 \pm 0.5$ & 1.0 & rf cosputtering & This work \\
\hline $\mathrm{Ag}$ & +0.27 & $50 \pm 10$ & $33 \pm 6$ & 4.8 & thermal evaporation & This work \\
\hline $\mathrm{Al}$ & +0.13 & $62 \pm 10$ & $34 \pm 6$ & 0.4 & thermal evaporation & This work \\
\hline $\mathrm{Al}$ & $\sim-0.08$ & 39 & 32 & 0.24 & thermal evaporation & 21 \\
\hline $\mathrm{Al}$ & +0.18 & - & 22 & 0.72 & sputtering & 23 \\
\hline $\mathrm{Cr}$ & $+0.7-+0.9$ & $100-180$ & $1-5$ & 0.22 & thermal evaporation & 22 \\
\hline $\mathrm{Fe}_{40} \mathrm{Ni}_{40} \mathrm{P}_{14} \mathrm{~B}_{6}$ & - & - & 10.8 & 50 & quenching & 50 \\
\hline $\mathrm{Fe}_{32} \mathrm{Ni}_{36} \mathrm{Cr}_{14} \mathrm{P}_{12} \mathrm{~B}_{6}$ & - & - & 13.5 & 50 & quenching & 50 \\
\hline $\mathrm{Fe}_{78} \mathrm{Mo}_{2} \mathrm{~B}_{20}$ & - & - & 8.6 & 50 & quenching & 50 \\
\hline$n c-\mathrm{Fe}_{78} \mathrm{~B}_{13} \mathrm{Si}_{9}$ & - & - & $14.1 \pm 0.5$ & $\sim 30$ & $\begin{array}{l}\text { annealing quenched } \\
\text { sample }\end{array}$ & 51 \\
\hline$a-\mathrm{Fe}_{78} \mathrm{~B}_{13} \mathrm{Si}_{9}$ & - & - & $7.4 \pm 0.5$ & $\sim 30$ & quenching & 51 \\
\hline$n c-\mathrm{Ni}-\mathrm{P}$ & - & - & $16-20$ & $\sim 20$ & $\begin{array}{l}\text { annealing quenched } \\
\text { sample }\end{array}$ & 52 \\
\hline$a-\mathrm{Ni}-\mathrm{P}$ & - & - & 14.2 & $\sim 20$ & quenching & 52 \\
\hline$n c-\mathrm{Se}$ & - & - & $9.5-12.5$ & - & $\begin{array}{l}\text { annealing quenched } \\
\text { sample }\end{array}$ & 53 \\
\hline
\end{tabular}

anaindentation data $\left(E / 1-\nu^{2}\right)$.

and 6, respectively. They show that the CTE of most films is higher than that of their corresponding crystalline, and the biaxial modulus is always smaller. In order to make it clear that the biaxial modulus of the thin films are smaller than those of the crystalline structures, we plotted Fig. 6 using the

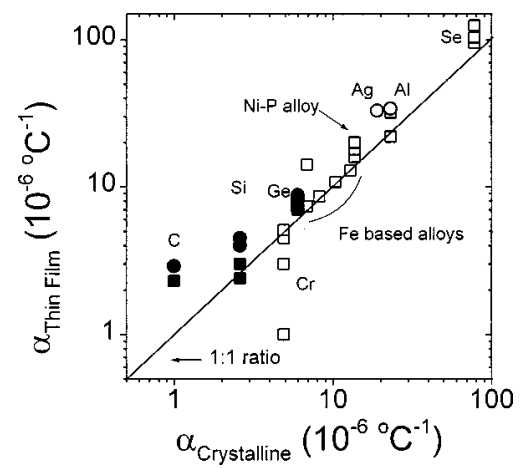

FIG. 5. Coefficient of thermal expansion of several amorphous semiconductors and metallic thin films compared with their crystalline counterpart. Circles are data from this work and squares are data obtained from the literature. The full points are amorphous semiconductors and the open points are metallic films. The straight line (slope one) represents the situation in which the CTE is equal to that of the crystalline. For additional information concerning the film properties shown, see Table II and references therein. crystalline orientation with the smallest biaxial modulus, i.e., $\langle 100\rangle .{ }^{34}$ Data reported by other laboratories are also included in these figures.

For metallic films, yielding and plastic flow hinder the determination of elastic constants by the TIB technique,

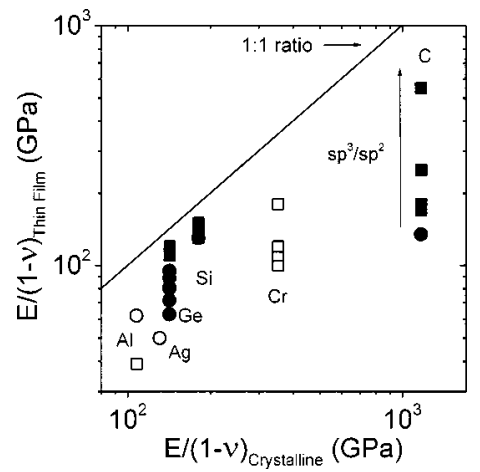

FIG. 6. Biaxial modulus of several amorphous semiconductors and metallic thin films compared with their crystalline counterparts. Circles are data from this work and squares are data obtained from the literature. The full points are amorphous semiconductors and the open points are metallic films. The straight line (slope one) represents the situation in which the biaxial modulus is equal to that of the crystalline. For additional information concerning the film properties shown, see Table II and references therein. 
which requires an elastic behavior. However, since we annealed all the samples before the measurements, the stress vs temperature dependence on the metallic films also shows linear elastic behaviors (see Fig. 2), allowing the use of the TIB technique. In the range of low temperature adopted in this work (from room temperature to $100^{\circ} \mathrm{C}$ ), a linear behavior has also been observed for other materials such as aluminum composites $^{49}$ and $\mathrm{Fe}$ alloys, ${ }^{24,50}$ measured while the temperature was cooling down, after an annealing step. And the same was observed for $\mathrm{NiP},{ }^{51} \mathrm{Fe}_{78} \mathrm{~B}_{13} \mathrm{Si}_{9},{ }^{52}$ and $\mathrm{Se},{ }^{53}$ synthesized by the annealing of a melt-quenched amorphous sample.

\section{DISCUSSIONS}

The stress of thin films has been associated with its structural properties. ${ }^{4,10,54,55}$ Films with tensile stress usually have a high density of defects, such as voids and columnar structures. This is probably the case of the tensile silver and aluminum films prepared by thermal evaporation (see Table II). It is well known that films deposited by this technique are usually tensile. ${ }^{4}$ On the other hand, films with compressive stress have better structural properties. For example, electronic quality $a-\mathrm{Si}: \mathrm{H}$ and $a-\mathrm{Ge}: \mathrm{H}$ films prepared by glow discharge are compressive, ${ }^{42,54}$ and a rough empirical relation between stress and electronic properties has already been observed for $a$-Ge:H. ${ }^{56}$ Even though no systematic study of $a-\mathrm{Si}: \mathrm{H}$ had been performed, a relation similar to that reported for $a-\mathrm{Ge}: \mathrm{H}$ is expected, judging by some partial results reported in the literature. ${ }^{10,57-59}$ Thus, the compressive stress obtained in our films prepared by sputtering, (Table II) is an indication that they have good structural properties. That is also supported by infrared spectroscopy, which does not show any absorption bands associated with contamination of the films several months after deposition.

The coefficient of thermal expansion of all films prepared in this work is higher than that of their crystalline counterparts (see Fig. 5, circles). For amorphous semiconductors, this trend stands for many other data reported in the literature, except for one $a$-Si:H reported by Volkert ${ }^{17}$ with a CTE smaller than that of $c$-Si. These differences are related to variations in the interatomic potential between the crystalline and amorphous phase, and between films with different structures. It is well known that amorphous semiconductors have structural defects such as dangling bonds, hydrogen, and voids, which alter the interatomic potential. In addition, after deposition, these kinds of materials frequently present internal stress that modifies the interatomic equilibrium position. Figure 7 shows the difference between the CTE of $a$-Si:H (or $a-\mathrm{Ge}: \mathrm{H}$ ) CTE of its correspondent in the crystalline phase, normalized by the CTE of the crystalline phase $\left(\Delta \alpha / \alpha_{s}\right)$, as a function of the stress of the sample. The behavior of both films is very similar, probably because they have very similar structures. It is interesting to observe that both materials show a clear tendency to reduce the CTE as the stress changes from compressive to tensile. Moreover, the CTEs of compressive films are higher than those of their corresponding crystalline semiconductors, but they are smaller for tensile films. This may explain why most re-

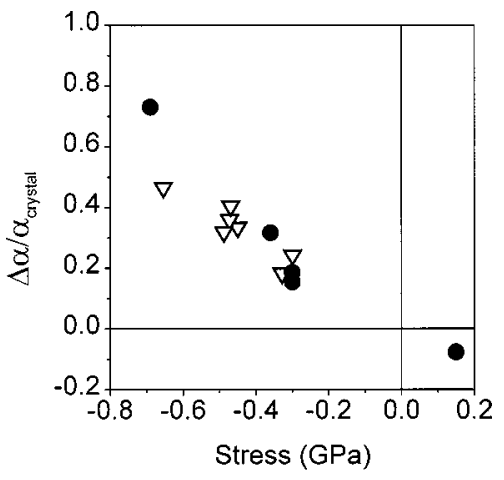

FIG. 7. The difference between the CTE of tetrahedral amorphous semiconductors and their crystalline counterparts normalized by the crystalline value ( $\Delta \alpha / \alpha_{\text {cryst }}$ ) as a function of the stress, which changes from compressive (positive values) to tensile (negative values). Full points are silicon samples and open points are germanium films (data from literature are included).

ported CTEs are higher than those of their corresponding crystalline (Fig. 5) since these measurements have been performed in good quality materials, most of them with compressive stress. The data also suggest another important property, i.e., unstressed amorphous silicon and germanium films have CTEs that are approximately equal to those of crystalline silicon and germanium, respectively. In other words, the changing from crystalline to amorphous structure does not significantly affect the thermal expansion coefficient. The deviation observed here is attributed mainly to the strain of the film network, rather than to the structural changes such as void-like defects, dangling bonds, and hydrogen concentration.

The dependence of the CTE on the stress is somehow expected. When a film has compressive stress, for instance, it means that the film expands itself along the substrate until it reaches equilibrium. In this case the film bonds are tensed, and their lengths become longer than those of their corresponding crystalline semiconductors. Thus, the interatomic potential is modified and the CTE is expected to change. A tension strain tends to make the interatomic potential more asymmetric around the minimum, such that an increase in the CTE is expected. The opposite should occur for films with tensile stress. In fact, a recent theoretical work by Fabian and Allen, ${ }^{60}$ using the Stillinger-Weber potential, predicted that the application of some strain in amorphous silicon bonds modifies its expansion coefficient. Even though they do not propose a specific model for its variation caused by the presence of macroscopic stress, the results shown in Fig. 7 for amorphous silicon films are in qualitative agreement with their prediction. The data for amorphous germanium have the same behavior, and should follow the same model, since $a-\mathrm{Ge}: \mathrm{H}$ and $a-\mathrm{Si}: \mathrm{H}$ have similar structures; both being tetrahedral covalent amorphous semiconductors. To better establish these finds of amorphous semiconductors more data are necessary, and a theoretical model to explain them is still needed.

The metallic films studied in this work, aluminum and silver, and almost all films reported in literature have CTEs higher than those of their crystalline counterpart. There are some exceptions, such as the series of chromium films re- 


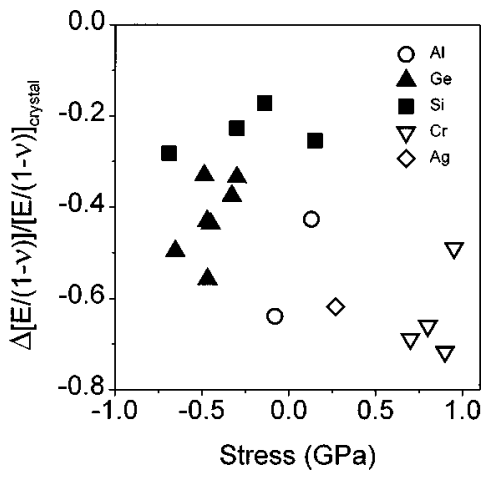

FIG. 8. The difference between the biaxial modulus of the amorphous and polycrystalline films and their crystalline counterparts normalized by the crystalline value as a function of the stress, which changes from compressive (positive values) to tensile (negative values). Full points are semiconductors and open points are polycrystalline films (data from literature are included).

ported by Janda, ${ }^{22}$ and aluminum reported by Kraft and Nix, ${ }^{23}$ see Fig. 5. No clear dependence of the CTE on the stress was observed. There must be other contributions to the change in the CTE of metallic films. A possible one could be the crystallinity of the films, as has been suggested in a study of Se, NiP, and Pd films ${ }^{51,53,61}$ (also included in Fig. 5). These works relate the CTE (measured by $\mathrm{x}$ ray) to the nanocrystal sizes. The CTE tends to increase when the grain size decreases. ${ }^{61}$ So, as the structure changes from monocrystalline (infinite grain size) to polycrystalline (the usual structure of thin metallic films) one should expect the expansion coefficient to increase, which is the case of most films. The amorphous phase (zero grain size), on the other hand, has been found to have a thermal expansion smaller than that of the nanocrystalline phase, ${ }^{51,52}$ but which is still higher than that of the crystalline phase. The chromium data do not fit in that explanation (see Fig. 5). However, even though these data have also been determined using the TIB technique, the samples were deposited on only one anisotropic substrate, and the curvature measurements were obtained only at the deposition (in some cases above $250^{\circ} \mathrm{C}$ ) and room temperature. ${ }^{22}$ Thus, it is not clear whether or not they have been measured in the elastic regime. In addition, they have very high tensile stress, which suggests that they may have suffered plastic deformation during the measurements. Of course the grain size is not the only feature contributing to the behavior of the thermal expansion. Crystallographic orientation and elastic anisotropy can also contribute to change the thermal expansion. More systematic studies need to be performed to clarify the behavior of the thermal expansion of metallic films.

The biaxial modulus of all films reported in this work and by other laboratories, (see Fig. 6) are smaller than those of their crystalline counterparts, which must be related to structural defects. One may think that the residual stress could also induce some changes in the elastic constants, as was observed in the CTE of the amorphous semiconductors. Figure 8 displays the reduction in the biaxial modulus normalized by their crystalline counterpart values, as a function of the stress. No clear dependence on the stress was observed for each series of films, although a rough trend is observed when we consider all films. However, this may not be associated with the network strain, but with the concentration of structural defects. As stated above, the stress is strongly related to defects, and tensile films are more defective than compressive films. Of course, the nature of the defects in polycrystalline metals is different from the one in amorphous semiconductors, but they both contribute to weaken the network rigidity.

The carbon films were not included in Fig. 8, since, as it is well known, $a-\mathrm{C}: \mathrm{H}$ films have different structures (polymeric, graphitic, and diamond-like) due to the carbon ability to make bonds with $s p^{3}, s p^{2}$, and $s p$ hybridization. However, their elastic constant can be explained by the change of the coordination number as modeled by $\mathrm{He}$ and Thorpe ${ }^{62}$ and observed experimentally by Robertson. ${ }^{63}$ It is observed (Fig. 6) that the biaxial modulus of $a-\mathrm{C}: \mathrm{H}$ films increases toward that of diamond, as the $s p^{3}$ concentration increases (i.e., as the coordination number increases). The elastic modulus of $a-\mathrm{C}: \mathrm{H}$ films is also affected by the hydrogen concentration, which contributes to the reduction in the average coordination number.

\section{CONCLUSION}

The coefficient of thermal expansion of $a-\mathrm{Si}: \mathrm{H}$ and $a$-Ge:H films seems not to be affected by the structural changes, from the crystalline to the amorphous phase. It was observed that it is much more influenced by the network strain, being higher than that of their corresponding crystalline semiconductors for films with compressive stress, and smaller for tensile films. The biaxial modulus of all films developed here and of all those reported in the literature are smaller than those of their crystalline counterpart. In order to understand better these properties of amorphous and metallic films, more data are necessary, and besides that, theoretical models to explain the finds of this work are still needed.

\section{ACKNOWLEDGMENTS}

This work has been supported by the Brazilian agencies FAPESP, CNPq, and PADCT.

${ }^{1}$ J. Robertson, Prog. Solid State Chem. 21, 199 (1991).

${ }^{2}$ R. W. Hoffman, Physics of Non-Metallic Thin Films (Plenum, New York, 1970), Vol. B-14.

${ }^{3}$ P. Wickboldt, S. J. Jones, F. C. Marques, D. Pang, W. A. Turner, A. E. Wetsel, W. Paul, and J. H. Chen, Philos. Mag. B 64, 655 (1991).

${ }^{4}$ D. S. Campbell, Mechanical properties of thin films, Handbook of Thin Film Technology (McGraw-Hill, New York, 1970), Chap. 12.

${ }^{5}$ F. C. Marques, P. Wickboldt, D. Pang, J. H. Chen, and W. Paul, J. Appl. Phys. 84, 3118 (1998).

${ }^{6}$ C. L. Kuo, P. E. Vanier, and J. C. Bilello, J. Appl. Phys. 55, 375 (1984).

${ }^{7}$ T. Iwaoka, S. Yokoyama, and Y. Osaka, Jpn. J. Appl. Phys., Part 1 24, 112 (1985).

${ }^{8}$ X. Jiang, J. W. Zou, K. Reichelt, and P. Grünberg, J. Appl. Phys. 67, 4729 (1990).

${ }^{9}$ X. Jiang, B. Goranchev, K. Schmidt, P. Grünberg, and K. Reichelt, J. Appl. Phys. 67, 6772 (1990).

${ }^{10}$ J. P. Harbison, A. J. Williams, and D. V. Lang, J. Appl. Phys. 55, 946 (1984).

${ }^{11}$ F. Rossi et al., J. Appl. Phys. 75, 3121 (1994)

${ }^{12}$ T. A. Friedmann, J. P. Sullivan, J. A. Knapp, D. R. Tallant, D. M. Folls- 
taedt, D. L. Medlin, and P. B. Mirkarimi, Appl. Phys. Lett. 71, 3820 (1997).

${ }^{13}$ R. Bhadra, J. Pearson, P. Okamoto, L. Rehn, and M. Grimsditch, Phys. Rev. B 38, 12656 (1988).

${ }^{14}$ P. J. Burnett and G. A. D. Briggs, J. Mater. Sci. 21, 1828 (1986).

${ }^{15}$ A. Witvrouw and F. Spaepen, J. Appl. Phys. 74, 7154 (1993).

${ }^{16}$ F. Jansen and M. A. Machonkin, J. Vac. Sci. Technol. A 6, 1696 (1988).

${ }^{17}$ C. A. Volkert, J. Appl. Phys. 74, 7107 (1993).

${ }^{18}$ I. A. Blech and P. Wood, J. Vac. Sci. Technol. A 11, 728 (1993).

${ }^{19}$ F. C. Marques, R. G. Lacerda, M. M. de Lima, Jr., and J. Vilcarromero, Phys. Status Solidi B 192, 549 (1995).

${ }^{20}$ R. G. Lacerda, M. M. de Lima, Jr., J. Vilcarromero, and F. C. Marques, in Surfaces, Vacuum, and Their Applications, edited by Hernández-Calderón and Asomoza (AIP, New York, 1996), p 315.

${ }^{21}$ M. Janda, Thin Solid Films 112, 219 (1984).

${ }^{22}$ M. Janda, Thin Solid Films 142, 37 (1986).

${ }^{23}$ O. Kraft and W. D. Nix, J. Appl. Phys. 83, 3035 (1998).

${ }^{24}$ A. Fujita, T. Suzuki, N. Kataoka, and K. Fukamichi, Phys. Rev. B 50, 6199 (1994)

${ }^{25}$ R. G. Lacerda and F. C. Marques, Appl. Phys. Lett. 73, 617 (1998).

${ }^{26}$ F. C. Marques and I. Chambouleyron, Proceedings of the 9th European Photovoltaic Solar Energy Conference, edited by W. Palz, G. T. Wrixon, and P. Helm (Kluwer Academic, Dordrecht, 1989), p. 1042.

${ }^{27}$ P. I. Rovira and F. Alvarez, Phys. Status Solidi B 192, 535 (1995).

${ }^{28}$ J. Vilcarromero, F. C. Marques, and F. L. Freire, J. Appl. Phys. 84, 174 (1998).

${ }^{29}$ V. Hoffman, Solid State Technol. 21, 47 (1978).

${ }^{30}$ B. A. Movchan and A. V. Demchishin, Fiz. Metal. Metaloved. 28, 653 (1969).

${ }^{31}$ J. A. Thornton, J. Vac. Sci. Technol. 11, 666 (1974).

${ }^{32}$ J. A. Thornton, J. Vac. Sci. Technol. 12, 830 (1975).

${ }^{33}$ R. F. Bunshan, J. Vac. Sci. Technol. 11, 633 (1974).

${ }^{34}$ W. A. Brantley, J. Appl. Phys. 44, 534 (1973).

${ }^{35}$ R. B. Roberts, J. Phys. D 14, L163 (1981).

${ }^{36}$ O. Madelung, M. Schulz, and H. Weiss, Landboldt-Börnestein Numerical data and Functional Relationships in Science and Technology (Springer, Berlin, 1982), Vol. III 17a.
${ }^{37}$ Data Supplied by the manufacturer, Corning Glass.

${ }^{38}$ Data Supplied by the manufacturer, Precision Glass.

${ }^{39}$ M. M. de Lima, Jr., Master degree thesis, Unicamp, Brazil, 1998; R. G. Lacerda, Master degree thesis, Unicamp, 1998.

${ }^{40}$ A. Witvrouw and F. Spaepen, MRS Spring Meeting San Francisco, CA, 1990.

${ }^{41}$ P. A. Flinn, D. S. Gardner, and W. D. Nix, IEEE Trans. Electron Devices ED-34, 689 (1987).

${ }^{42}$ M. Stutzmann, Appl. Phys. Lett. 47, 21 (1985).

${ }^{43}$ G. C. Stoney, Proc. R. Soc. London, Ser. A 32, 172 (1909).

${ }^{44}$ R. W. Hoffman, Physics of Thin Films (Academic, New York, 1966), Vol. 3.

${ }^{45}$ T. F. Retajczyk, Jr. and A. K. Sinha, Appl. Phys. Lett. 36, 161 (1980).

${ }^{46} \mathrm{~S}$. Guo and W. Wang, Thin Solid Films 219, 135 (1992).

${ }^{47}$ T. F. Retajczyk, Jr. and A. K. Sinha, Thin Solid Films 70, 241 (1980).

${ }^{48}$ S. P. Murarka and T. F. Retajczyk, Jr., J. Appl. Phys. 54, 2069 (1983).

${ }^{49}$ A. L. Geiger and P. Welch, J. Mater. Sci. 32, 2611 (1997).

${ }^{50}$ J. E. Shelby, J. Non-Cryst. Solids 34, 111 (1979).

${ }^{51}$ K. Lu and M. L. Sui, Acta Metall. Mater. 43, 3325 (1995).

${ }^{52}$ H. Y. Tong, J. T. Wang, B. Z. Ding, H. G. Jiang, and K. Lu, J. Non-Cryst. Solids 150, 444 (1992).

${ }^{53}$ Y. H. Zhao and K. Lu, Phys. Rev. B 56, 14330 (1997).

${ }^{54}$ W. A. Turner et al., J. Appl. Phys. 67, 7430 (1990).

${ }^{55}$ M. Maeda and K. Ikeda, J. Appl. Phys. 83, 3865 (1998)

${ }^{56}$ P. Wickboldt, F. C. Marques, S. J. Jones, D. Pang, W. A. Turner, and W. Paul, J. Non-Cryst. Solids 137, 83 (1991).

${ }^{57}$ J. Kocka and M. Vanecek, Mater. Res. Soc. Symp. Proc. 95, 83 (1987).

${ }^{58}$ M. Stutzmann, W. B. Jackson, and C. C. Tsai, Mater. Res. Soc. Symp. Proc. 49, 301 (1985).

${ }^{59}$ W. E. Spear and M. Heintze, Philos. Mag. B 54, 343 (1986).

${ }^{60}$ J. Fabian and P. B. Allen, Phys. Rev. Lett. 79, 1885 (1997).

${ }^{61}$ J. A. Eastman and M. R. Fitzsimmons, J. Appl. Phys. 77, 522 (1995).

${ }^{62}$ H. He and M. F. Thorpe, Phys. Rev. Lett. 54, 2107 (1985).

${ }^{63}$ J. Robertson, Phys. Rev. Lett. 68, 220 (1992). 